\title{
Cell cycle-dependent cytotoxic and cytostatic effects of bortezomib on colon carcinoma cells
}

\author{
Cell Death and Differentiation (2006) 13, 873-875. doi:10.1038/sj.cdd.4401881; published online 24 February 2006
}

\section{Dear Editor,}

Bortezomib is a specific inhibitor of the $\mathrm{S} 20$ proteasome ${ }^{1}$ and acts as a prominent inducer of apoptosis that is now clinically approved for the treatment of multiple myeloma. ${ }^{2}$ Ongoing preclinical and clinical studies suggest that bortezomib might also be used for the treatment of a variety of additional hematological and epithelial cancers. ${ }^{3}$ The inhibition of the proteasome greatly perturbs cellular metabolism and can lead to the accumulation of a variety of toxic proteins including the BH3 only protein Noxa. ${ }^{4-6}$ Moreover, bortezomib can inhibit the degradation of the inhibitor of $\mathrm{NF}-\kappa \mathrm{B}$ protein $\left(\mathrm{I}_{\kappa} \mathrm{B}\right)$, thereby leading to the suppression of NF- $\kappa$ B activation. ${ }^{7}$ Indeed, this $\mathrm{NF}-\kappa \mathrm{B}$ inhibition by bortezomib has constituted the principal rationale for the search of therapeutic indications for the agent. $^{8}$ In spite of its increasing experimental and therapeutic use, little is known about cell cycle-specific effects of bortezomib.

One intrinsic difficulty in determining cell cycle-specific effects of proapoptotic drugs is that most protocols used for the enrichment of cells in defined phases of the cell cycle are based on the synchronization with toxic compounds or nonphysiological culture conditions that affect the apoptotic threshold of cells. ${ }^{9}$ We developed a procedure for the purification of nonsynchronized cells in distinct phases of the cell cycle. This method is based on the stable transfection of cells with a chimeric protein made up by histone H2B and green fluorescent protein (GFP). Cytofluorometric purification of exponentially growing cells defined by their forward scatter characteristics (which reflects cell size) and their H2B-GFPdependent fluorescence (which reflects chromatin and hence DNA content) allowed for the enrichment of live, functional cells in the $\mathrm{G} 1, \mathrm{~S}$ and $\mathrm{G} 2$ phases of the cell cycle. The distinct populations purified in the fluorescence-activated cell sorter (FACS), labeled 'G1', 'S' and 'G2' (Figure 1a) were subjected to a quality control in which DNA/chromatin content was assessed by conventional methods (such as staining with Hoechst 33342) (Figure 1b), DNA synthesis was assessed by measuring 5-bromo-2-deoxyuridine (BrdU) (Figure 1c) or the intracellular concentration of cyclins such as cyclin B1 was measured by immunofluorescence analyses (Figure 1d). These control experiments suggested that $\mathrm{G} 1, \mathrm{~S}$ and $\mathrm{G} 2$ phase cells were purified to $>95 \%, \sim 70 \%$ and $\sim 60 \%$, respectively (Figure $1 \mathrm{~b}-\mathrm{d}$ ). Moreover, these cells failed to undergo apoptosis spontaneously (see below) and readily resumed the cell cycle upon reculture (not shown).

We determined whether NF- $\kappa \mathrm{B}$ might be regulated differentially in the G1, S or G2 phases of the cell cycle. We found that approximately $40 \%$ of RKO colon carcinoma cells spontaneously contained the p65 NF- $\kappa \mathrm{B}$ subunit in the nucleus (Figure 1e) and that this percentage was increased in G2 (but not G1 or S) (Figure 1f). Upon short-term culture with bortezomib, the frequency of cells with positive nuclear p65 staining was strongly reduced to $<20 \%$, and this bortezomib effect was seen in all phases of the cell cycle (Figure 1f). Importantly, there was a positive correlation between nuclear cyclin B1 staining and p65 NF- $\kappa$ B staining, as determined by immunofluorescence staining of nonsynchronized, nonpurified cells (Figure 1g,h). This confirmed that the cells tended to activate NF- $\kappa \mathrm{B}$ in the $\mathrm{G} 2$ phase more frequently than in any other phase of the cell cycle. Of note, since we used adherent cells as the starting material of our cell cycle fractionation assays, there were little if any $(<0.1 \%)$ mitoses in our cultures, and most (>99\%) of the G2 phase cells were negative for mitotic markers such as MMP3 (not shown) or phosphorylated histone $\mathrm{H3}$ (H3P) (Figure 2e). Thus, the activation of NF- $\kappa \mathrm{B}$ is likely to occur in a truly $\mathrm{G} 2$ phase-specific fashion.

Next, we investigated the effects of bortezomib on G1, S and $\mathrm{G} 2$ cells. There was a marked cell cycle-specific trend in the reduction of cellular mass induced by two drugs that inhibit $\mathrm{NF}-\kappa \mathrm{B}$, namely bortezomib (Figure $2 \mathrm{a}, \mathrm{b}$ ) and the IKK inhibitor BAY-117082 (not shown). In response to both agents, cells in the G2 phase were much more affected in an assay that determined the total metabolic activity (reduction of the tetrazolium salt WST-1). This strong effect was observed only in short-term $(20 \mathrm{~h}$ ) experiments (Figure $2 \mathrm{a}$ ), presumably because the cell cycle specificity disappears when cells resume proliferation upon long-term $(40 \mathrm{~h}$ ) culture (Figure $2 \mathrm{~b}$ ). Next, we investigated the mechanisms through which bortezomib might preferentially compromise the growth/ survival of cells in the G2 phase. On theoretical grounds, this might be either due to the preferential apoptosis of $\mathrm{G} 2$ cells or due to cell cycle-specific cytostatic effects. First, we determined the degree of caspase-3 activation, by measuring the frequency of cells staining positively with an antibody that recognizes the large subunit of activated caspase-3. Driven by the idea that bortezomib would mainly act as an apoptosis inducer, ${ }^{2,7}$ we expected that this proteasome inhibitor would lead to preferential caspase-3 activation in G2. However, bortezomib induced a similar degree of caspase-3 activation in $\mathrm{G} 1, \mathrm{~S}$ and $\mathrm{G} 2$ as in the total cell population (Figure 2c). In this respect, bortezomib behaved similar to staurosporin, which acts a cell-cycle-independent apoptosis inducer. In 
a
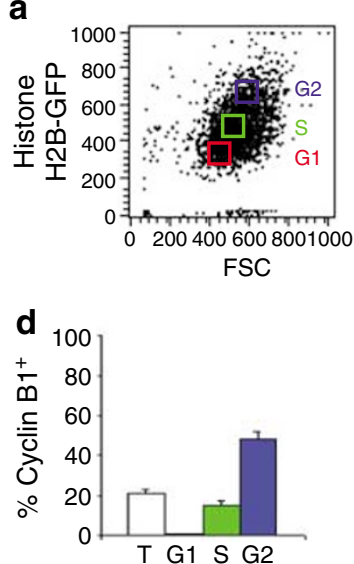

b

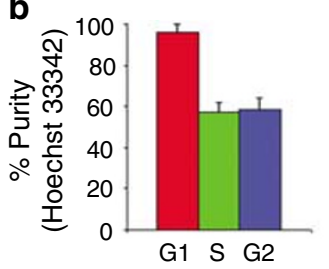

C

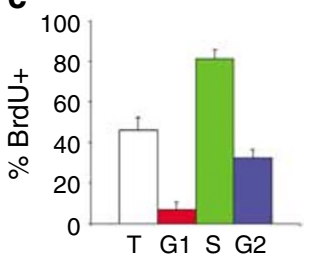

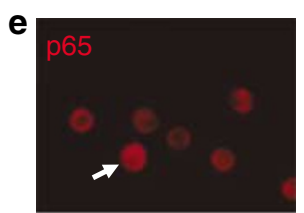

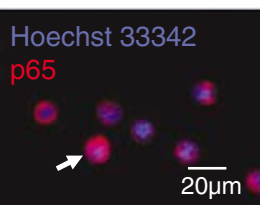

p65
Cyclin B1

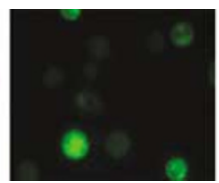

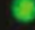
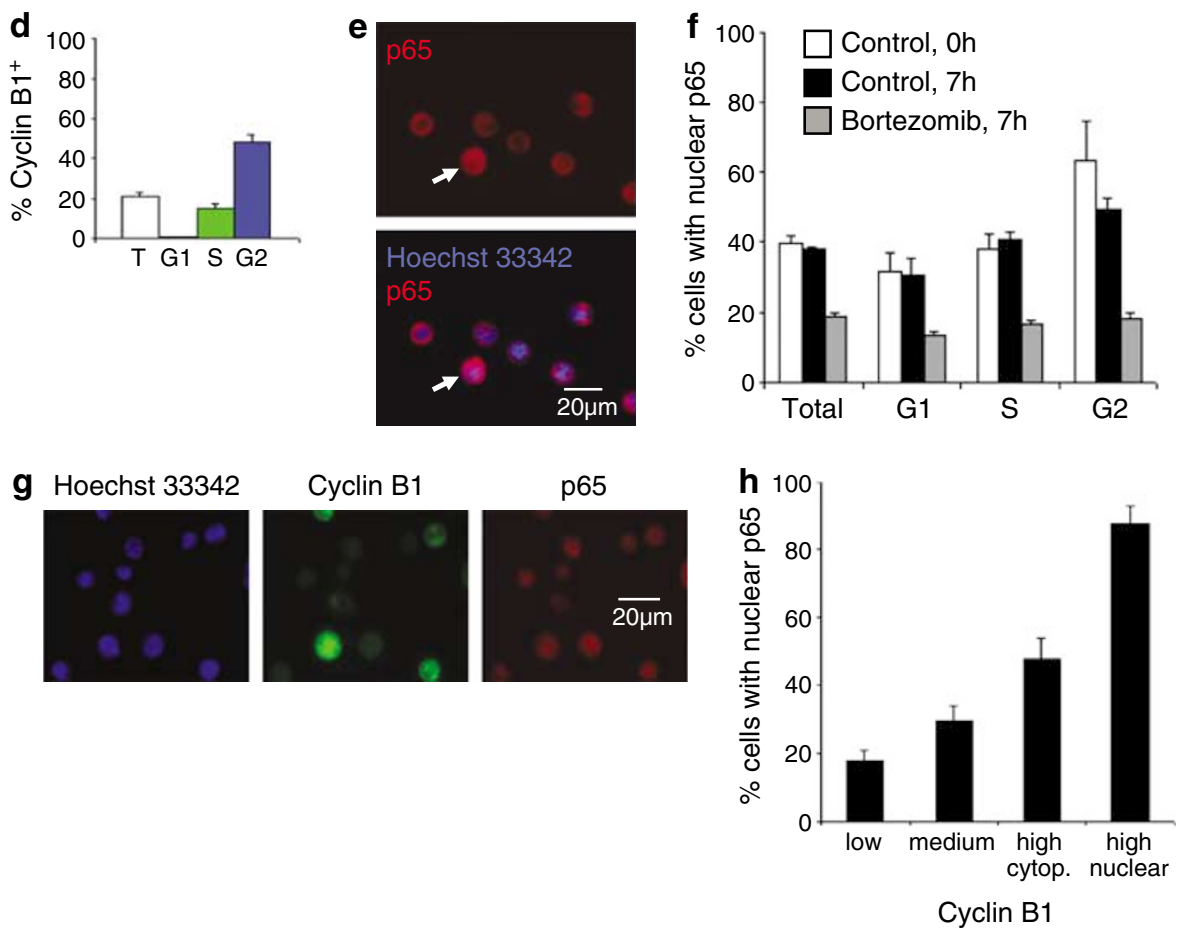

Figure 1 Cell cycle dependency of the accumulation of p65 in the nucleus. (a-d) A method for the enrichment of nonsynchronized cells in distinct phases of the cell cycle. An RKO cell clone stably transfected with a commercially available H2B-GFP fusion construct (Pharmingen) was cultured in Mac Coy medium supplemented with $10 \%$ fetal calf serum. The cells in the exponential phase of the cell cycle were washed, trypsinized and subjected to simultaneous detection of the cell size (forward scatter, FSC) and the H2B-GFP fluorescence (a) in a fluorescence activated cell sorter (FACS). Cells found in either of the three gates ('G1', 'S', 'G2') were purified in a FACS Vantage from Becton \& Dickinson equipped with a $70 \mu \mathrm{m}$ nozzle and CellQuest software. Then, the cells were subjected to three types of quality control, namely measurement of the DNA/chromatin content with Hoechst $33342\left(2 \mu \mathrm{M}, 30 \mathrm{~min}\right.$ at $37^{\circ} \mathrm{C}$, Molecular Probes) to determine the relative purity of each of the populations (b), incorporation of 5-bromo-2-deoxyuridine (BrdU, $30 \mu \mathrm{M}, 15 \mathrm{~min}$, Sigma) ${ }^{12}$ that only incorporates into cells during the $\mathrm{S}$ phase of the cell cycle (c), or fixation and permeabilization for the detection of cyclin B1 with a specific monoclonal antibody (Transduction Laboratories). ${ }^{13}$ (e-f) Subcellular localization of p65 in distinct phases of the cell cycle. Cells that were not separated (total) or purified as a function of the cell cycle (as in a-d) were subjected to the immunofluorescence detection of the NF- $\kappa \mathrm{B}$ subunit p65, as described. ${ }^{14} \mathrm{~A}$ representative example of the p65 staining of cells found in the G2 phase of the cell cycle is shown in $\mathbf{e}$, and the frequency of cells possessing p65 in the nucleus (white arrows in e) were determined for each phase of the cell cycle (f). As an additional control, cells were cultured for $7 \mathrm{~h}$ in the presence of bortezomib $(40 \mathrm{nM})$, leading to reduced nuclear p65 in all phases of the cell cycle, as compared to control cultures maintained in the absence of bortezomib. ( $\mathbf{g}-\mathbf{h}$ ) Colocalization of p65 and cyclin B1 in the nucleus. Nonsynchronized and nonpurified cells were stained simultaneously with Hoechst 33342 and for the detection of cyclin $\mathrm{B} 1$ and nuclear p65 $(\mathbf{g})$. The percentage of cells with nuclear p65 staining was determined among cells differing in their cyclin B1 staining (g). Results are means (X) of three experiments \pm standard deviation $(\mathrm{SD})$

contrast, there was a clear trend for enhanced apoptosis of S-phase cells when camptothecin was used as an apoptosis inducer, as to be expected from previous studies, ${ }^{10,11}$ thus validating the idea that our experimental set-up can be used to detect cell cycle-specific apoptosis induction (Figure 2c). Next, we measured the capacity of bortezomib to arrest the cell cycle. Bortezomib induced an accumulation of cells in the G2 phase (Figure 2d), coupled to a massive increase in cyclin B1-positive cells, yet a reduction of cells staining with the mitotic marker H3P (Figure 2e). In conclusion, bortezomib caused an arrest of the cell cycle at the G2/M border, yet had no cell cycle specificity in its proapoptotic activity.
The data contained in this paper unravel a novel, hitherto unsuspected specificity in the activation of $N F-\kappa B$ that appears to be particularly strong in the G2 phase of the cell cycle. Correlating with the enhanced translocation of the $\mathrm{p} 65 \mathrm{NF}-\kappa \mathrm{B}$ subunit, cells in the $\mathrm{G} 2$ phase are particularly susceptible to the growth-inhibitory effect of bortezomib. However, in this system, bortezomib appears to act mainly as a growth inhibitor (and as an inhibitor of the $\mathrm{G} 2 \rightarrow \mathrm{M}$ transition) rather than as a selective apoptosis inducer. These data raise important questions on the putative cell cycle-modulatory effects of the NF- $\mathrm{B}$ system in human cancer. Further studies performed in a 

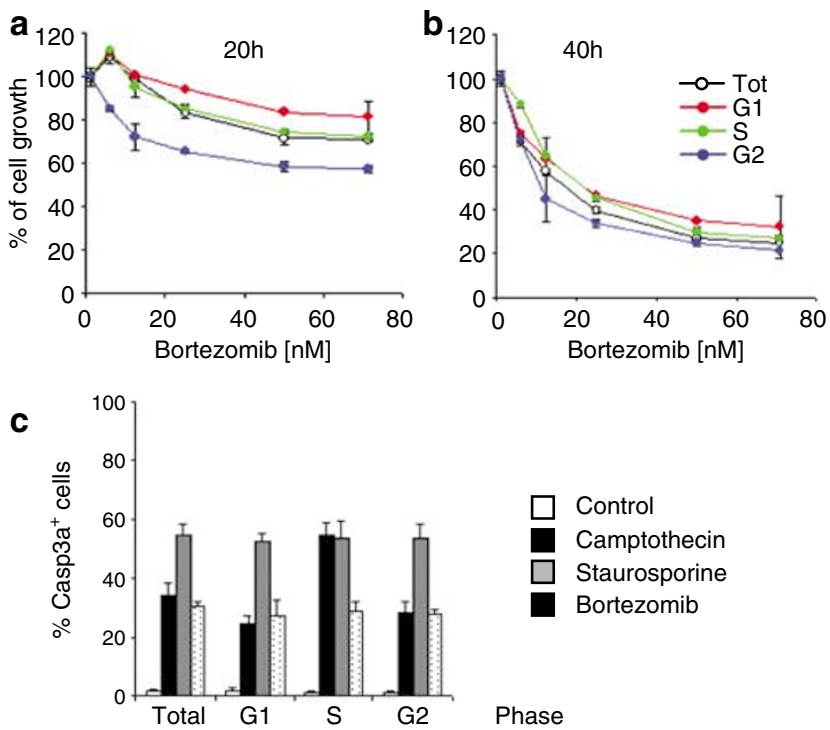

d
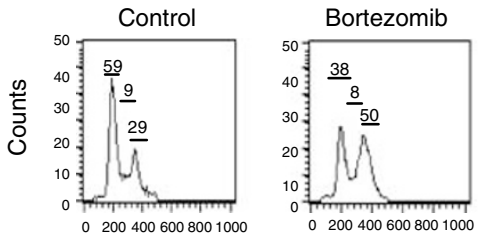

Hoechst 33342
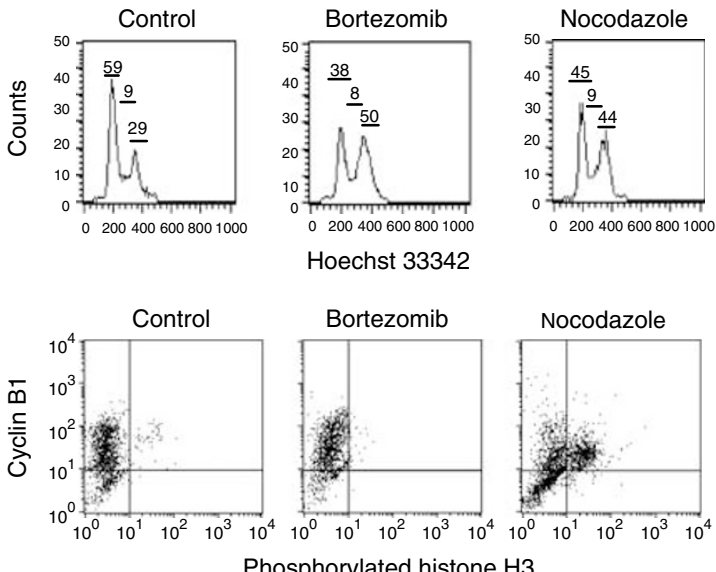

Figure 2 Cell cycle-specific effects of bortezomib. (a-b) Cell cycle dependent growth inhibition by bortezomib. Cells in distinct phases of the cell cycle (purified as in 1a-f) were cultured in the indicated conditions, in the absence or in the presence of the indicated concentrations of bortezomib for $20 \mathrm{~h} \mathrm{(a)}$ or for $40 \mathrm{~h}(\mathbf{b})$. Then, a colorimetric assay for quantification of cell viability $(X+S D, n=3)$ based on the reduction of the tetrazolium salt WST-1 (Roche Diagnostics, Germany) was employed. (c) Cell cycle-dependent caspase activation induced by various apoptosis inducers. Cells purified as above were cultured overnight in the absence or presence of camptothecin $(40 \mu \mathrm{M})$, staurosporine $(150 \mathrm{nM})$ or bortezomib $(50 \mathrm{nM})$, and the cells were subjected to immunofluorescence detection of activated caspase-3 (Casp-3a) using a specific antibody (Asp175; Cell Signaling Technology), as described. ${ }^{15}$ (d-e) Effects of bortezomib on cell cycle advancement. RKO cells were cultured in the absence or in the presence of bortezomib ( $50 \mathrm{nM}, 8 \mathrm{~h}$ ) or nocodazole ( $3 \mu \mathrm{M}, 8 \mathrm{~h})$, followed by cell cycle analysis by two alternative methods, namely Hoechst 33342 staining for the determination of DNA content (d) or a double staining for the simultaneous detection of cyclin $\mathrm{B} 1$ and phosphorylated histone $\mathrm{H} 3$ (e). Numbers in $\mathbf{d}$ refer to the percentages of cells in the G1, S and G2/M phases. These experiments have been repeated twice, yielding similar results variety of distinct cellular models should address this problem in the future.

\section{Acknowledgements}

GK is supported by European Commission (Active p53), Cancéropôle lle-de-France, Fondation Laurette Fugain, Fondation de France, and Association pour la Recherche contre le cancer. S.M. received a fellowship from Institut Gustave Roussy.

\section{A Coquelle ${ }^{1}$, S Mouhamad ${ }^{1}$, MO Pequignot ${ }^{1}$, T Braun $^{1}$, G Carvalho ${ }^{1}$, Vivet $^{1}$, D Métivier $^{1}$, M Castedo $^{1}$ and G Kroemer ${ }^{*, 1}$}

${ }^{1}$ Centre National de la Recherche Scientifique, UMR8125, Institut Gustave Roussy, 39 rue Camille-Desmoulins, Villejuif, France

* Corresponding author: G Kroemer, Centre National de la Recherche Scientifique, UMR8125, Institut Gustave Roussy, Pavillon de Recherche 1, 39 rue Camille Desmoulins, Villejuif F-94805, France. Tel: 331421160 46; Fax: 331421160 47; E-mail: kroemer@igr.fr

1. Karin $\mathrm{M}$ et al. (2004) Nat. Rev. Drug Discov. 3: 17-26.

2. Hideshima T et al. (2002) J. Biol. Chem. 277: 16639-16647.

3. Green DR and Kroemer G (2005) J. Clin. Invest. 115: 2610-2617.

4. Perez-Galan P et al. (2006) Blood 107: 257-264.

5. Fernandez $Y$ et al. (2005) Cancer Res. 65: 6294-6304.

6. Qin JZ et al. (2005) Cancer Res. 65: 6282-6293.

7. Cusack JCJ et al. (2001) Cancer Res. 61: 3535-3540.

8. Karin M (2002) Nat. Rev. Cancer 2: 301-310.

9. Castedo M et al. (2002) Cell Death Differ. 9: 1287-1293.

10. Gorczyca W et al. (1993) Cancer Res. 53: 1945-1951.

11. Johnson N et al. (1997) Leuk. Res. 21: 961-972.

12. Gonzalo JA et al. (1994) J. Immunol. 152: 1597-1608.

13. Castedo $\mathrm{M}$ et al. (2002) EMBO J. 21: 4070-4080.

14. Braun T et al. (2006) Blood 107: 1156-1165.

15. Perfettini JL et al. (2005) J. Exp. Med. 201: 279-289. 